\title{
Estudi de cas sobre el tractament integrat del verb en una aula d'educació secundària
}

\author{
Marina Casadellà \\ Universitat Autònoma de Barcelona, Barcelona, Espanya
}

Article rebut 27 de març 2015, acceptat 19 setembre 2015, versió final 20 octubre 2015

DOI: http://dx.doi.org/10.5565/rev/jtl3.626

\begin{abstract}
Resum
Aquesta investigació parteix de la tesi que és positiu dur a terme un tractament integrat en l'ensenyament de llengües, però cal veure fins a quin punt aquesta afirmació ha tingut una incidència sobre la pràctica docent diària. L'objectiu d'aquest estudi és ajudar a trobar-hi una resposta a través d'una anàlisi comparativa sobre l'ensenyament del verb en llengua catalana i en llengua castellana en una aula de secundària obligatòria. L'estudi comprovarà que a l'aula analitzada no es porta a terme un tractament integrat de les llengües durant el procés d'ensenyament $\mathrm{i}$ aprenentatge del verb. Conseqüentment, els resultats d'aquesta breu investigació evidencien de manera clara la necessitat imperant d'establir vincles profunds entre la recerca en didàctica de la llengua $\mathrm{i}$ la pràctica docent executada a les aules.
\end{abstract}

Paraules clau: Tractament integrat de llengües, ensenyament del verb, didàctica de la llengua

\begin{abstract}
Resumen
Este estudio parte de la tesis de que es positivo realizar un tratamiento integrado en la enseñanza de lenguas, pero es necesario ver hasta qué punto esta afirmación ha tenido una incidencia sobre la práctica docente diaria. El objetivo de este estudio es ayudar a encontrar una respuesta a través de un análisis comparativo sobre la enseñanza del verbo en lengua catalana y en lengua castellana en una aula de secundaria obligatoria. El estudio comprobará que en el aula analizada no se lleva a cabo un tratamiento integrado de ambas lenguas durante el proceso de enseñanza y aprendizaje del verbo. En consecuencia, los resultados de esta breve investigación evidencian de manera clara la necesidad imperante de establecer vínculos profundos entre la investigación en didáctica de la lengua y la práctica docente ejecutada en las aulas.
\end{abstract}

Palabras clave: Tratamiento integrado de lenguas, enseñanza del verbo, didáctica de la lengua

\begin{abstract}
This paper is based on the assumption that it is positive to teach languages in an integrated way. Nevertheless, we must find out to what an extent this statement has an incidence on the daily practice of teachers. The main goal of this research is to find an answer to this question by means of a comparative analysis about the way Catalan and Spanish verbs are taught in secondary school. This study will verify that there is no integrated teaching of those languages whenever verbs are taught as a grammatical concept. Consequently, the results of this short research will show that it is really necessary to build
\end{abstract}


strong links between the research in both languages teaching and actual teaching practices which take place at the classroom.

Keywords: Integrated treatment of languages, teaching verbs, language teaching

\section{Introducció}

Fent una immersió en les diferents línies que ha seguit la recerca en didàctica de la llengua al llarg dels anys, podem veure que una part important dels esforços s'ha destinat a explorar el tractament integrat de llengües. Aquest terreny, que podria semblar reduït, aglutina un ventall immens de conceptes, definicions i idees que són el resultat d'anys de dedicació d'un gran nombre de persones. Aquest estudi, com veurem de manera més desenvolupada al marc teòric, entén el tractament integrat com la programació i planificació conjunta de l'ensenyament de diverses llengües.

La recerca realitzada fins el moment mostra que existeix un cert consens entre investigadors sobre els factors positius que aporta un tractament integrat de llengües. Partint d'aquesta idea inicial, la investigació que ens ocupa voldrà comprovar si hi ha un traspàs entre allò que aconsella la recerca, en general, i allò que realitzen els docents a la seva aula: concretament, es vol analitzar quin és el grau de treball en tractament integrat de llengües en una aula de secundària. Així mateix, tenint en compte la realitat social i lingüística que ens acompanya, s'ha volgut centrar l'estudi en el tractament integrat de les assignatures de català i castellà, com a llengües presents en la vida quotidiana dels estudiants.

\section{Marc teòric}

Durant els últims anys, s'han esdevingut una sèrie de canvis estructurals de tipus social que han tingut una incidència molt directa en els processos d'ensenyament i d'aprenentatge de llengües a les nostres escoles. Guasch (2007) parla de tres factors de canvi fonamentals: el factor sociolingüístic, el factor tecnològic i el factor psicolingüístic. En el nostre cas, ens interessa especialment definir els factors sociolingüistic i psicolingüístic.

Pel que fa al factor sociolingüistic, Guasch el presenta per dues raons diferents: la primera fa referència al fet que en els darrers anys hi ha hagut un canvi important d'expectatives respecte l'aprenentatge de llengües: actualment es considera indispensable el coneixement de llengües estrangeres, en especial de l'anglès. La segona, en canvi, pren en 
consideració el canvi social viscut després de les darreres onades migratòries, que han suposat un augment significatiu de la diversitat de llengües primeres que es poden trobar en una mateixa aula.

Per altra banda, Guasch (2007) incideix més profundament en l'explicació del factor psicolingüístic, per al qual tenen una especial importància les característiques específiques del coneixement lingüístic dels plurilingües (Pascual, 2006). Segons Guasch (2007), aquest coneixement específic es pot tipificar a partir de quatre particularitats pròpies dels plurilingües. En primer lloc, parlaríem d'una ampliació dels sabers lingüístics, a diferència del coneixement dels monolingües. Els plurilingües tenen la capacitat d'establir comparacions entre les diverses llengües, i així trobar-ne les seves similituds i diferències. En segon lloc, cal tenir en compte que totes les llengües comparteixen algunes característiques específiques, sobre les quals no cal efectuar nous aprenentatges cada vegada que s'inicia l'estudi d'un nou llenguatge. Així, doncs, alguns coneixements concrets es poden fer extensius a totes les llengües. En tercer lloc, l'autor apunta la connexió entre els coneixements lingüístics, fent referència a la relació entre significant i el significat de les paraules. Aquest punt defensa que les representacions dels significats que es fan els aprenents no varien en funció de la llengua que estiguin utilitzant. En l'aprenentatge de nous conceptes lingüístics, no se substitueixen els significats coneguts prèviament, sinó que es busca la manera d'integrar-los en la relació significant-significat que ja es tenia assumida abans de l'aprenentatge de la nova llengua. Finalment, l'autor fa esment de les modificacions dels sabers lingüístics pròpiament dits respecte el coneixement que tenen els monolingües. Aquest fet es justificaria, per una banda, entenent que en l'aprenentatge de segones llengües es passa per un procés de presa de consciència específica dels processos lingüístics; i, per altra banda, perquè la recerca de connexions entre una llengua i l'altra indueix a una "redefinició de les representacions sobre els sistemes lingüístics apresos amb anterioritat”. (Guasch, 2007, p. 141)

Així, doncs, la nostra recerca parteix de la base que és positiu i necessari que existeixi una coordinació en la planificació de l'ensenyament de les llengües catalana i castellana. Aquesta coordinació configura el tractament integrat de llengües, que fa referència a dos aspectes: la planificació de la matèria d'ensenyament de les llengües des d'una única perspectiva didàctica i la programació conjunta per aprofitar les coincidències entre llengües, afavorir les complementarietats i evitar les repeticions (Guasch, Gracia i Carrasco, 2004). El 
fet de trobar positiu el tractament integrat es justifica per estudis que tracten la connexió dels sistemes lingüístics en la ment dels usuaris. Herdina i Jessner (2002) consideren que els coneixements lingüístics de persones que dominen més d'un idioma no es poden equiparar a la suma dels coneixements que tenen els monolingües.

La recerca que ens ocupa pretén comprovar si en un cas concret es porta a terme un tractament integrat de l'ensenyament i aprenentatge del verb. Ribas (2010) parla de les diferents perspectives en què es podria enfocar aquest ensenyament. Dues de les perspectives citades són les següents: perspectiva sintàctica i perspectiva morfològica. La primera és la perspectiva que

tracta el verb com un element que selecciona els arguments en funció de les valències del verb i que defineix el subjecte i els complements verbals com unes marques formals determinades. (Ribas, 2010:59)

En canvi, des de la perspectiva morfològica s'entén que el verb és una pròpia unitat amb unes determinades categories que permeten realitzar l'anomenada conjugació verbal.

\section{Pregunta i objectius de la recerca}

La pregunta inicial de la recerca es formula de la següent manera:

Quins punts de contacte $i$ quines diferències s'observen en el plantejament didàctic de l'ensenyament de la noció de verb d'un professor de llengua catalana i una professora de llengua castellana de 2 n d'ESO?

En la mateixa línia, els objectius generals de la recerca són els següents:

- Comprovar si es porta a terme un tractament integrat de llengües a l'aula de secundària estudiada.

- Conèixer les semblances i diferències entre els plantejaments didàctics d'un professor estudiat i de l'altre.

- Conscienciar el professorat de llengües de l'aula analitzada de la importància d'establir coordinacions entre ells, incitant la reflexió sobre la seva pròpia tasca.

\section{Justificació metodològica de la recerca}

Metodològicament, aquesta recerca presenta clares proximitats amb la definició que alguns autors (Latorre, Del Rincón i Arnal, 2003) proposen de l'estudi de cas: segons afirmen, aquest tipus de recerca és particularment apropiat per estudiar una situació amb certa intensitat en un 
període de temps curt. Així mateix, els autors afegeixen que el potencial de l'estudi de cas radica en què permet centrar-se en una situació concreta, així com identificar els diversos processos interactius que la conformen. Amb tot, ens trobem davant d'una recerca que, a la vegada, també presenta característiques pròpies d'altres mètodes d'investigació, com són l'etnografia (Laplatine, 1996; Palou, 2008) o la investigació avaluadora (Merriam, 1988).

Pel que fa a l'escenari de recerca, la recollida de dades es va dur a terme a través d'una sola aula d'alumnes, un grup de segon curs d'ESO. En referència als participants, vam enregistrar un grup de vint alumnes de segon curs d'ESO -tretze i catorze anys-. Així mateix, el professorat implicat incloïa dos docents de l'àmbit de les llengües: un professor de llengua catalana i una professora de llengua castellana.

La recollida de dades es va basar en dos elements principals que quedaven complementats: el punt de vista directe del professorat i el desenvolupament d'una sessió de cadascuna de les assignatures. Díaz i Velasco (1997) afirmen que aquesta complementarietat es pot justificar amb la necessitat de contrastar allò que diuen i allò que fan realment els participants. En el nostre cas, aquestes afirmacions es van traduir en l'enregistrament, l'observació i l'anàlisi de dues sessions d'aula - una per a cada matèria- i de dues entrevistes una per a cada docent-.

Les dues sessions es van gravar el mateix dia i la matèria que es tractava era la mateixa en les dues assignatures: la qüestió del verb. En els dos casos era el primer dia del curs que s'abordava aquest punt del temari, de manera que tots dos professors van iniciar la sessió amb una petita introducció de com es desenvoluparia la qüestió en les diferents sessions en què la treballarien.

L'anàlisi de dades va consistir a comparar el desenvolupament de les dues sessions, en funció de les seqüències respectives en què es podien dividir. En primer 1loc, es va realitzar una comparació sobre l'organització de les dues sessions, en base a la seva divisió seqüencial. Aquesta divisió va ser efectuada en funció de les activitats que es realitzaven i de les diferents accions que conduïen la sessió, generalment executades de manera conscient pel professor de la matèria. En conseqüència, cada nova acció o activitat empresa pel docent representa una nova seqüència. Seguidament, es va aprofundir en l'anàlisi de dues seqüències concretes, una de cada assignatura. Així mateix, es va efectuar una anàlisi i comparació de les diverses activitats que es portaven a terme en les respectives sessions. 
Pel que fa al punt de vista del professorat, vam fer dues entrevistes semi-estructurades, individuals i breus, una a cadascun dels professors. L'objectiu de les entrevistes era obtenir la visió concreta i específica dels dos professors implicats per tal de veure'n semblances i diferències. Aquesta recerca pretenia establir punts en comú i punts discordants entre els dos participants, de manera que les entrevistes es van dur a terme de manera individual i per separat, malgrat que el guió inicial fos el mateix, amb l'objectiu que les respostes d'un docent no interferissin en les contestacions de l'altre.

\section{Anàlisi de les dades: les sessions d'aula}

Tot seguit, presentem una taula resum de les dues sessions, així com una breu descripció de les seqüències en què vam dividir-les.

\begin{tabular}{|l|l|l|l|}
\hline \multicolumn{1}{|l|}{ LLENGUA CASTELLANA } \\
\hline \multicolumn{1}{|c|}{ Seqüència } & \multicolumn{1}{|c|}{ Intervencions } & \multicolumn{1}{c|}{ Durada } & \multicolumn{1}{c|}{ Títol } \\
\hline 1 & $1-6$ & 45 segons & Inici: introducció \\
\hline 2 & $6-121$ & 15 minuts & Exposició de la matèria \\
\hline 3 & $122-174$ & 4 minuts & Assignació de la tasca \\
\hline 4 & $175-365$ & 20 minuts & Realització d'exercicis \\
\hline 5 & $365-385$ & 1 minut & Tria d'alumnes que corregeixen \\
\hline 6 & $386-435$ & 6 minuts & Feina per la setmana següent \\
\hline 7 & $436-507$ & 7 minuts & Correcció d'exercicis \\
\hline
\end{tabular}

Quadre 1. Seqüències de la sessió de Llengua Castellana

1. Inici: introducció: presentació del temari que es tractarà durant la sessió. La professora afirma que treballaran el sintagma verbal.

2. Exposició de la matèria: durant quinze minuts, la professora exposa el contingut que apareix el llibre de text amb el suport d'un projector. La professora va presentant la matèria $\mathrm{i}$ en moments puntuals es va aturant fer alguna pregunta als alumnes o per demanar-los que completin la informació.

3. Assignació de la tasca: la professora demana als alumnes que obrin el llibre per una pàgina determinada alhora que reparteix unes fotocòpies on s'hi reprodueix el paradigma verbal. Tot seguit, assigna uns quants exercicis del llibre que els alumnes hauran de resoldre.

4. Realització d'exercicis: durant vint minuts, els alumnes resolen els exercicis assignats.

La professora serveix de suport als alumnes quan tenen dubtes per dur a terme la tasca. 
5. Tria d'alumnes que corregeixen: la professora anuncia que procediran a corregir els exercicis i assenyala dos estudiants perquè surtin a la pissarra a escriure la seva resolució de les activitats.

6. Feina per la setmana següent: mentre els dos estudiants resolen les activitats a la pissarra - una cadascun-, la professora informa dels exercicis del llibre de text que els alumnes hauran de tenir fets per a la propera sessió.

7. Correcció d'exercicis: la professora se serveix de les activitats de la pissarra per fer-ne la correcció, tot assenyalant quines respostes són correctes i quines no ho són.

\begin{tabular}{|l|l|l|l|}
\hline \multicolumn{2}{|l|}{ LLENGUA CATALANA } \\
\hline Seqüència & \multicolumn{1}{|c|}{ Intervencions } & \multicolumn{1}{|c|}{ Durada } & \multicolumn{1}{c|}{ Títol } \\
\hline 1 & $1-36$ & 2 minuts & Inici: posada al dia del Diari d'aula \\
\hline 2 & $36-86$ & 3 minuts & Presentació del tema i preparació dels materials \\
\hline 3 & $87-115$ & 3 minuts & Lectura col·lectiva del text \\
\hline 4 & $115-164$ & 3 minuts & Identificació dels verbs \\
\hline 5 & $165-225$ & 2 minuts & Exposició dels verbs identificats \\
\hline 6 & $226-298$ & 5 minuts & Projecció de text \\
\hline 7 & $299-589$ & 20 minuts & Característiques del verb \\
\hline 8 & $590-697$ & 5 minuts & Preguntes sobre la temàtica \\
\hline 9 & $697-709$ & 3 minuts & Lliurament d'exercicis \\
\hline 10 & $709-777$ & 5 minuts & Joc final \\
\hline
\end{tabular}

Quadre 2. Seqüències de la sessió de Llengua Catalana

1. Inici: posada al dia del Diari d'aula: el professor fa una valoració del Diari d'aula que ha rebut aquella setmana i decideix quins alumnes l'hauran de fer per la setmana següent.

2. Presentació del tema i preparació dels materials: el professor informa que durant aquella sessió estudiaran el verb. Tot seguit, fa un control d'assistència i demana a una alumna que reparteixi unes fotocòpies amb un text escrit.

3. Lectura col-lectiva del text: els alumnes llegeixen en veu alta, en torns repartits assignats pel professor, el text que han rebut. Es tracta d'un Diari d'aula escrit setmanes abans per un estudiant d'aquell mateix grup.

4. Identificació dels verbs: el professor dóna als alumnes cent trenta segons per marcar els verbs que trobin fins a la desena línia.

5. Exposició dels verbs identificats: el professor fa que els alumnes diguin quins verbs han trobat i que justifiquin per què consideren que cada paraula escollida és un verb. El professor recull algunes de les justificacions a la pissarra. 
6. Projecció del text: el professor projecta el text i va assenyalant els verbs de les deu primeres línies.

7. Característiques del verb: el professor escriu quatre característiques del verb, dues de les quals són aportacions que els alumnes havien fet a la cinquena seqüència i que ell havia recollit a la pissarra.

8. Preguntes sobre la temàtica: el professor reparteix uns trossos de paper on hi ha escrit alguns dels termes que han tractat al llarg de la sessió. En rebre el paper, els alumnes han de definir la qüestió que s'hi planteja.

9. Lliurament d'exercicis: el professor fa arribar als alumnes unes fotocòpies amb una sèrie d'exercicis que hauran de fer autònomament per a la propera sessió.

10. Joc final: per acabar, realitzen conjuntament un joc que el professor té preparat a l'ordinador en què es fan preguntes sobre la matèria treballada.

La diferència principal que trobem en el plantejament de les dues sessions descrites és en la pròpia estructura general que presenten. En el cas de la sessió de llengua castellana, veiem que es divideix en un nombre reduït de seqüències llargues. Trobem, doncs, que la majoria de les seqüències tenen una durada de més de cinc minuts. Fins i tot podríem apuntar que la sessió es troba dividida en tres apartats principals: l'exposició de la matèria -Seqüència 2, de quinze minuts-, la realització dels exercicis (Seqüència 4 de vint minuts) i la correcció dels exercicis -Seqüències 6 i 7, de sis i set minuts respectivament-. La resta de les seqüències són introductòries quant a la matèria a tractar i a les tasques a realitzar. La sessió de llengua catalana, en canvi, es caracteritza per presentar deu seqüències curtes: la gran majoria tenen una durada d'entre dos i cinc minuts.

Per tal d'efectuar l'anàlisi de les seqüències, ens vam centrar en una en concret per a cadascuna de les sessions. Vam considerar que el més oportú era escollir-ne una en què apareixien explícitament els nous continguts proposats per a la sessió. D’aquesta manera, es va poder copsar fàcilment com es va dur a terme la presentació de continguts. Així, doncs, vam prendre com a base la Seqüència 2 de llengua castellana -Exposició de la matèria- i la Seqüència 7 de llengua catalana -Característiques del verb-.

En aquestes dues seqüències podem constatar que hi ha grans diferències en la manera com apareixen els continguts, així com pel que fa al contingut treballat. A la de llengua 
castellana, Exposició de la matèria, hi trobem una estructura de transmissió de coneixements basada en tres fases que es repeteixen amb constància:

1- Explicació unidireccional dels nous conceptes. Es realitza una lectura textual del llibre que tenen els alumnes, amb el suport d'un projector. En algunes ocasions, l'explicació es reforça amb informació addicional per part de la professora.

2- La professora fa una pregunta directa al gran grup en relació amb alguna de les qüestions que acaba d'exposar.

3- Els alumnes contesten. Si la resposta és incorrecta, la professora corregeix, o bé deixa una altra oportunitat a l'alumnat. Si la resposta és correcta, la professora amplia la matèria o bé prossegueix a tractar alguna altra qüestió.

Amb aquesta estructura concreta, els continguts que afloren són de caire molt divers. Així, doncs, es tracten els següents conceptes: sintagma verbal, nucli del sintagma verbal, definició del verb, complements verbals, lexema i morfema, flexió -incorporant el temps, la persona, el nombre i el mode-; inclouria seguidament un petit aprofundiment en el mode tractant-ne les diferents tipologies -indicatiu, subjuntiu i imperatiu-, veu activa i veu passiva $\mathrm{i}$, per últim, verbs regulars i verbs irregulars. Finalment, en acabar tota l'exposició, la professora fa una pregunta directa a l'alumnat demanant si ho han entès. Tot seguit, mostrem un exemple de dades obtingudes en aquesta seqüència.

Extracte 1. Exemple de dades de la seqüència Exposició de la matèria

106. PROF: am $\backslash$ vale/ y en el verbo bailar/ (..)

107. ALM1: ba/

108. ALG: bail

109. PROF: y en el verbo cantar/

110. ALG: can\}

111. PROF: exactamente si tú ten- lo que eliminamos en la terminación del infinitivo $\backslash$ (.) de acuerdo/ todo esto es el lexema $\backslash$ y no hay ninguna irregularidad en el lexema/ y tampoco hay irregularidad/ a la hora/ de conjugar de acuerdo/ (.) entonces ((llegeix)) los morfemas flexivos son los mismos que los verbos/los del verbo modelo de su conjugación $\backslash$ y en el recuerda los verbos regulares no presentan ninguna variación en el lexema los morfemas flexivos son iguales que los verbo modelo de su conjugación (XXX) (.) tenéis alguna duda/

112. ALM1: no

En canvi, en el cas de llengua catalana l'exposició de continguts s'estructura de manera diferent: 
1- El professor pren dues de les característiques del verb que ja han esmenat anteriorment els alumnes, quan ell els havia preguntat com havien sabut identificarlos.

2- Introdueix l'absència de gènere com a tercera característica del verb:

a. El professor fa un recordatori dels tipus de paraules tractats en sessions anteriors i les separa els mots en funció de si tenen gènere o no.

b. Proposa exemples de paraules perquè els alumnes diguin tenen gènere o no.

c. Finalment, escriu a la pissarra la tercera característica del verb.

3- Posa com a exemple les oracions ja escrites a la pissarra per mostrar la quarta característica del verb (Sense verb no hi ha oració).

4- Síntesi de les característiques del verb.

5- Tractament de conceptes addicionals.

Així, doncs, els continguts que apareixen en aquesta seqüència són, principalment, quatre característiques del verb: Es pot posar en infinitiu; És flexible; No té gènere; Sense verb no hi ha oració. Per altra banda, es fa una breu introducció a continguts addicionals, esmentant la veu, activa i passiva, i l'aspecte, perfectiu o imperfectiu. Seguidament, també mostrem un exemple de dades obtingudes en aquesta seqüència.

Extracte 2. Exemple de dades de la seqüència Característiques del verb

429. PROF: què vol dir/ que sense verb no hi ha oració/ com podem fer una oració sense un verb/a veure qui em fa un verb/ una oració sense un verb/

430. ALM1: pilota

431.TOTs:@@@

432. ALM2: la mesa

433. PROF: quina oració és aquesta/ pilotal

434. ALM1: pilota blanca

435. PROF: però si tu li dius $\backslash$ tu imagina't

436. ALM3: eso es una frase

437. PROF: que el josep que és l'alumne aplicat de la classe: tu: i sempre contesta bé: tu li dius \{(F)pilota:\} 
438.ALG:@@@

439. PROF: tots ho heu entès (.) però en el fons què estàs dient-li/ ets un pilota $\backslash$ passa que el ets un no apareix eh:

Per tant, podem comprovar que els continguts varien molt significativament entre una llengua i l'altra, i en cap cas no s'estableix el mateix sistema de relació entre els continguts. Per altra banda, podem constatar una diferència important quant a l'ordre d'exposició de continguts. En el cas de llengua castellana, els continguts són exposats prèviament, oferint després el torn de paraula a l'alumnat per les seves pròpies aportacions. A la sessió de llengua catalana, en canvi, la concreció de la informació es fa de manera posterior al torn de paraula dels alumnes.

\section{Anàlisi de les dades: les activitats}

Per tal d'establir les semblances i diferències de les sessions descrites, es va prendre especial atenció a les activitats que es duien a terme. En el cas de l'assignatura de llengua castellana, les activitats eren les següents:

- Activitats 1 i 2: es resolen dos exercicis del llibre de text. Les activitats consisteixen a identificar el sintagma verbal d'una determinada oració i a assenyalar el seu respectiu nucli Seqüència 4-. Per tant, ens trobem davant de dues activitats que tenen una relació directa amb els continguts exposats anteriorment per la professora. Els exercicis en qüestió són els següents:

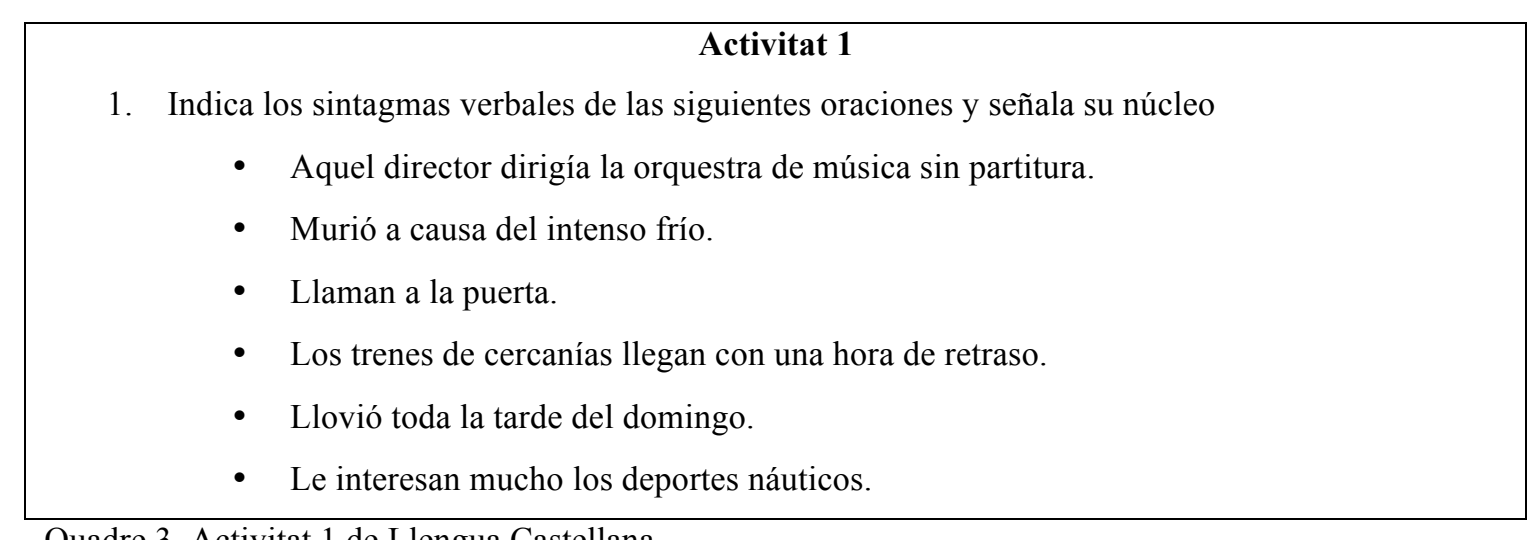

Quadre 3. Activitat 1 de Llengua Castellana 


\section{Activitat 2}

2. Forma cinco verbos con los siguientes lexemas y morfemas. A continuación, en tu cuarderno, completa con ellos y de forma coherente las oraciones; finalmente, destaca el sintagma verbal de cada una.

\begin{tabular}{c}
\hline jug-, -ió, corr-, -aba, ir-, -e, particip-, com-, \\
-emos, -an
\end{tabular}

- Alberto al fútbol esta mañana.

- Ayer, el atleta velozmente.

- Nosotros a Alicante de vacaciones

- Silvia muchos helados.

- Todos mis amigos en el concurso.

Quadre 4. Activitat 2 de Llengua Castellana

En canvi, en el cas de l'assignatura de llengua catalana, les activitats són les següents:

- Activitat 1: la primera activitat que apareix a la sessió és el Diari d'aula -Seqüència 1-. Es tracta d'un diari conjunt que han anat elaborant els alumnes al llarg de tot el curs, en què expliquen què fan i com viuen cadascuna de les sessions de llengua catalana. Cada dia s'assigna a algú diferent la tasca d'explicar i valorar aquella determinada sessió, de manera que finalment tot el grup compartirà un sol Diari d'aula de tota la feina que han fet durant el curs.

- Activitat 2: consisteix a identificar els verbs d'un text que el professor facilita Seqüència 4-. Concretament, es tracta d'un text de Diari d'aula de setmanes anteriors, i el professor deixa dos minuts per realitzar la tasca basant-se en les primeres deu línies d'aquell escrit. Abans de dedicar-se a identificar els verbs, hauran llegit col·lectivament tot el text en veu alta -Seqüència 3-.

- Activitat 3: consisteix a definir conceptes que tenen a veure amb la qüestió del verb Seqüència 8-. El professor reparteix a alguns alumnes una sèrie de trossos de paper on hi ha determinades paraules escrites. Un cop ha acabat de repartir, demana als alumnes que tenen paper quina paraula hi ha escrita al seu tros i quina definició en donarien. 
- Activitat 4: El professor dedica els cinc últims minuts de la sessió a fer una activitat col·lectiva de preguntes, imitant el programa televisiu ¿Quién quiere ser millonario? Seqüència 10-. Les preguntes que es presenten són les següents:

- Quantes persones gramaticals té un verb?

- Els modes personals del verb són...?

- Quines són les formes no personals?

- Tercera persona del present d'indicatiu del verb cantar.

- Imperfet d'indicatiu del verb cantar.

- Passat perifràstic del verb portar.

- Futur del verb portar.

- Condicional del verb portar.

- Subjuntiu del verb portar.

- Imperatiu del verb portar.

Per tal d'identificar les diferències principals entre cadascuna de les activitats proposades, prenem com a referència la tipologia proposada per Barbeiro (1999), segons la qual hi ha tres tipus diferents d'activitats quant a l'aprenentatge lingüístic:

a) Reconeixement/identificació d'unitats lingüístiques.

b) Producció de material lingüístic a partir d'indicacions metalingüístiques relatives a les propietats de les unitats que s'han de produir.

c) Explicitació o demostració efectiva d'un coneixement explícit sobre la llengua.

Tot seguit, presentem la distinció de cada activitat dins la tipologia esmentada:

\begin{tabular}{|l|c|c|}
\hline \multicolumn{1}{|c|}{ Llengua } & Castellà & Català \\
\hline Tipologia & \multicolumn{1}{|c|}{ Activitat 1 } \\
\hline $\begin{array}{l}\text { Reconeixement/identificació } \\
\text { d'unitats lingǘstiques }\end{array}$ & Activitat 2 (segona part) & Actitat 2 \\
\hline $\begin{array}{l}\text { Producció de material lingǘstic a } \\
\text { partir d'indicacions } \\
\text { metalingüístiques relatives a les } \\
\text { propietats de les unitats que s'han de } \\
\text { produir }\end{array}$ & Activitat 2 (primera part) & \\
\hline $\begin{array}{l}\text { Explicitació o demostració efectiva } \\
\text { d'un coneixement explícit sobre la } \\
\text { llengua }\end{array}$ & & Activitat 3 \\
\hline
\end{tabular}

Quadre 5. Tipologia d'activitats de Llengües Catalana i Castellana 
Com podem veure, les dues assignatures presenten diferències quant a la distribució d'activitats segons la tipologia de Barbeiro esmentada. En el cas de llengua castellana, trobem dues activitats del primer tipus -reconeixement-, una activitat del segon -producció- i cap activitat del tercer -demostració efectiva-. Per contra, les activitats de llengua catalana es troben dividides en tots els tipus esmentats. Concretament, trobem una activitat que respondria al primer -reconeixement-, una activitat que respondria al segon -producció-, i dues activitats que respondrien al tercer -demostració efectiva-.

Així, doncs, veiem que en el cas de llengua castellana, la línia metodològica principal, pel que fa a les activitats, se centra en la primera tipologia: el reconeixement i la identificació de les unitats lingüístiques. Aquest fet es contraposa a la inexistència d'activitats on es faci una demostració efectiva del coneixement explícit sobre la llengua, que és, precisament, el tipus d'activitat que predomina en el cas de llengua catalana. A més, malgrat que es duguin a terme exercicis de tots els tipus, en el cas de l'assignatura de llengua catalana hi destaquen els dos exercicis destinats a la demostració efectiva del coneixement, en contraposició amb les altres dues activitats, que formarien part de les dues tipologies restants, respectivament.

De l'anàlisi comparativa entre les sessions i les activitats, podem extreure'n una altra diferència important entre matèries. Concretament, fem referència a l'objecte declaratiu que s'ensenya en les dues sessions. A la conceptualització teòrica de l'article destacàvem que tindríem en compte principalment dues de les perspectives definides: la perspectiva sintàctica i la perspectiva morfològica (Ribas, 2010). Aquesta ha estat una diferència cabdal copsada en les dades obtingudes, sobre un plantejament didàctic i un altre respecte l'ensenyament del verb.

En el cas de la llengua catalana, s'inicia la sessió presentant que l'objecte que treballaran serà el Verb. Efectivament, tota la sessió es dedica a tractar les característiques del verb i la seva identificació dins de l'oració. Així doncs, es treballen en profunditat les qüestions de la conjugació verbal, de l'absència de gènere, de la persona i el nombre i de la necessitat d'aparició d'un verb per la formulació d'oracions. Per altra banda, també se cita, tot i que amb menys profunditat, l'aspecte verbal, les veus activa i passiva i la flexibilitat verbal. A més, en una ocasió, a causa de la intervenció d'un alumne, també s'anomena la perífrasi verbal. Per tant, es pot constatar que en aquest cas l'estudi del verb es fa principalment des de la perspectiva morfològica, tot afegint-hi alguns elements de la perspectiva sintàctica. Es 
treballa el verb com un dels elements de l'oració, amb les seves característiques pròpies i les seves estratègies d'identificació.

Pel que fa a la llengua castellana, es presenta que l'objectiu de la sessió serà treballar el Sintagma verbal. A través del llibre de text es tracta la definició de sintagma verbal i les seves característiques. En aquest cas, el verb és un element més del sintagma verbal i és com a element del sintagma verbal que es descriuen les característiques del verb: la seva pròpia definició -tractant bàsicament el verb com a acció-, el lexema i el morfema, la persona, el temps, el nombre i el mode. Es posa especial atenció a diferenciar la modalitat verbal, mitjançant exemples que proposa la professora partint d'una mateix oració i construint-la en modes diferents. Així, doncs, en aquest cas l'estudi del verb es fa des d'una perspectiva sintàctica.

\section{Anàlisi de les dades: les entrevistes}

Tot seguit, presentem les preguntes dutes a terme al llarg de les entrevistes, amb una comparació entre les respostes dels dos professors:

\section{Com organitzes la programació del curs?}

El primer tret diferencial que trobem entre una organització i l'altra és el punt de partida. En el cas de llengua catalana, el curs s'organitza a partir del currículum, sense fer ús del llibre de text ni de cap altre element intermediari, i en el cas de llengua castellana el curs sí que s'organitza a partir del llibre de text. La professora de llengua castellana és crítica amb l'organització interna dels llibres de text, i el professor de llengua catalana directament no el fa servir.

Per altra banda, la professora de llengua castellana afirma organitzar-se segons les unitats del llibre, encara que no li agradi com estan distribuïdes. A partir d'aquí, selecciona què treballarà i què no. Contràriament, el professor de llengua catalana expressa que un llistat d'allò que el currículum exigeix que es tracti, tot diferenciant entre els continguts i les competències. Segons diu, els continguts els distribueix segons la divisió trimestral del curs i les competències les treballa de manera transversal.

\section{Què és el més important que han d'aprendre els teus alumnes?}

El professor de llengua catalana afirma que el més important és aprendre a escriure, a parlar i a comprendre. Per la seva banda, en canvi, la professora de castellà determina que el més important és escriure correctament. Tots dos presenten les seves pròpies dificultats, tot i que 
siguin de caire divers: el professor de llengua catalana accentua la poca implicació de les famílies en l'ensenyament dels alumnes i destaca el paper cabdal que juga el centre per cobrir aquesta mancança. La professora de llengua castellana esmenta la influència de la llengua catalana en l'escriptura dels alumnes.

En tots dos casos es mostra un interès per la promoció d'exercicis d'escriptura, i diuen que l'apliquen en la seva tasca docent. Cadascun, però, ho fa per pal-liar problemàtiques diferents: el professor de llengua catalana pretén esmenar així la manca de suport familiar; en canvi, la professora de llengua catalana insisteix a promoure la producció pròpia com a contrapartida pels exercicis que es troba al seu llibre de text, la majoria de caire molt mecànic.

Per últim, la professora de llengua castellana incorpora en el seu discurs la importància de la diversitat dels gèneres discursius a l'hora de treballar la composició escrita. El professor de llengua catalana no fa esment a aquesta qüestió.

\section{Com planteges l'ensenyament $i$ aprenentatge del verb?}

El professor de llengua catalana afirma basar-se en les composicions escrites dels mateixos alumnes com a punt de partida per enumerar les característiques bàsiques del verb. Concretament, fa esment a l'absència de gènere del verb i a la seva flexió com a elements importants a treballar. Distingeix explícitament entre verbs d'acció i verbs d'estat i prepara activitats als alumnes perquè n'aprenguin la diferència. Per altra banda, com a pràctica, treballa les activitats de producció escrita, fent que siguin redactades en diversos temps verbals. La professora de llengua castellana, en canvi, treballa les quatre unitats del llibre de text dedicades a l'ensenyament del verb. Pren molta importància la memorització del paradigma verbal per part dels alumnes. Per tal d'assolir aquest objectiu, la professora ha realitzat activitats atractives per l'alumnat que han fet enfortir la motivació dels discents i, conseqüentment, han facilitat la memorització.

A més, el professor de català introdueix una petita reflexió sobre la importància de l'ensenyament de les categories gramaticals. El docent exposa els seus dubtes sobre fins a quin punt és important i necessari tenir un coneixement d'aquestes categories per millorar la composició escrita.

\section{Has tingut en compte el que es treballava a català/castellà??}

Tots dos professors contesten negativament aquesta pregunta. La professora de llengua castellana afirma sentir-se limitada pel fet que el castellà no sigui la seva especialitat. El 
professor de llengua catalana afegeix que alguna vegada ha aprofitat els comentaris dels alumnes per conèixer els continguts treballats a llengua castellana i fer-hi alguna menció a l'aula.

\section{Heu fet -o teniu previst- algun treball conjunt durant el curs?}

Els dos professors contesten negativament, tot i que no troben que sigui una mala idea. El professor de llengua catalana pensa que en un futur se'n podria plantejar la possibilitat. Afirma que a ell li agradaria ser la persona que ho coordinés i fa esment de la dificultat que suposa la manca de temps. La professora de llengua castellana, en canvi, fa referència a la seva pròpia especialitat -llengua francesa- per afirmar que ella té més facilitat per trobar punts en comú amb aquesta llengua. Per altra banda, també incorpora la possibilitat d'integrar altres disciplines, externes a les llengües, per establir una coordinació conjunta.

\section{Conclusions}

La primera conclusió que podem extreure fa referència a les diferències en la línia pedagògica que segueix cadascun dels docents per realitzar la seva tasca. La professora de llengua castellana realitza una metodologia d'aula basada en l'aprenentatge deductiu de la matèria, en què els coneixements són transmesos de manera parcialment unidireccional. La metodologia emprada en el cas de la llengua catalana, en canvi, promou que els coneixements siguin assolits de manera inferencial mitjançant diverses accions: per una banda, el docent fa un ús recursiu dels elements de suport, usant materials creats anteriorment a la mateixa aula. A més a més, el professor promou que siguin els mateixos alumnes els qui indueixin els nous coneixements en base tot allò que ja saben -sigui implícitament o explícita-.

Una altra diferència cabdal a tenir en compte és l'objecte declaratiu que cadascun dels professors treballa. No només trobem diferències sobre com s'ensenya, sinó també sobre què s'ensenya. Ja hem esmentat en apartats anteriors que en el cas de la llengua catalana es treballa el verb -perspectiva morfològica, amb alguns aspectes sintàctics- i en el cas de la llengua castellana es treballa el sintagma verbal -perspectiva sintàctica-. Aquest fet podria denotar que existeix certa coordinació entre el professorat, si creguéssim que els docents volen treballar les dues perspectives i que han estat presentades d'aquesta manera per mutu acord. Les dades recollides, però, ens mostren que no estem davant d'un cas d'aquestes característiques, per diverses raons: en primer lloc, sabem del cert, gràcies a les entrevistes, 
que no ha estat un fet explícitament intencionat. Els docents no s'han repartit les tasques i no han establert cap vincle de treball comú. Així mateix, també veiem, a les sessions d'aula, que no s'estableixen relacions entre les perspectives: no hi ha enllaços concrets que ajudin els alumnes a entendre el sistema relacional entre els conceptes.

Aquestes conclusions ens permeten afirmar que, en el cas del centre educatiu de referència, i concretament al nivell acadèmic estudiat -segon curs d'ESO-, no es porta a terme un tractament integrat de llengües. Per tant, malgrat que la recerca que ha estudiat aquesta qüestió fins al moment proposi el contrari, no existeix una coordinació real entre els professors de català i de castellà del cas que s'ha pres com a referència.

\section{Referències bibliogràfiques}

Barbeiro, L. (1999). Funcionamento da língua as dimensões activadas a partir dos manuais escolares. A Rui Vieira de Castro (dir.) Manuais escolares: estatuto, funções, história (p. 95-110). Braga: Universidade do Minho.

Díaz, A., \& Velasco, H. (1997). La lógica de la investigación etnográfica: Un modelo de trabajo para etnógrafos de la escuela. Madrid: Trotta.

Guasch, O., Gracia, C., \& Carrasco, P. (2004). L'aspecte verbal en les narracions de fícció. Una reflexió metalingüística. Articles de Didàctica de la Llengua i la Literatura, 33, 57-58.

Guasch, O. (2007). La educación multilingüe: un reto para el profesorado. Cultura y Educación, 19 (2), 135-147.

Herdina, P, \& Jessner, U. (2002). A dynamic model of multilingualism. Clevedon: Multilingual Matters.

Laplatine, F. (1996). La description ethnographique. París: Nathan.

Latorre, A., Del Rincón, D., Arnal, J. (2003). Bases metodológicas de la investigación educativa. Barcelona: Ediciones Experiencia.

Merriam, S. (1988). Case study research in education. A qualitative approach. San Francisco: Jossey-Bass.

Palou, J. (2008). L'ensenyament i l'aprenentatge del català com a primera llengua a l'escola: Creences $i$ actuacions els mestres amb relació a les activitats de llengua oral a l'etapa primària. Barcelona: Institut d'Estudis Catalans.

Pascual, V. (2006). El tractament de les llengües en un model d'educació plurilingüe per al sistema educatiu valencià. València: Conselleria de Cultura, Educació i Esport. Generalitat Valenciana.

Ribas, T. (2010). Aprender sobre el verbo en cuatro lenguas. Análisis de la noción de verbo en cuatro manuales de lenguas distintas de $3^{\circ}$ de ESO. Dins T. Ribas (coord.), Libros de texto y enseñanza de la gramática (p. 55-75). Barcelona: Graó. 
Informació de l'autora:

Marina Casadellà ha finalitzat els estudis de Llicenciatura en Pedagogia (2012) i del Màster de Recerca en Didàctica de la Llengua i la Literatura (2013) a la Universitat Autònoma de Barcelona. Actualment, és investigadora predoctoral del grup de recerca GREAL i professora del Departament de Didàctica de la Llengua, la Literatura, i de les Ciències Socials de la UAB. La seva Tesi Doctoral en curs estudia la formació continuada del professorat de llengües en un context de comunitat d'aprenentatge.

Email: marina.casadella@uab.cat

Per citar aquest article:

Casadellà, M. (2015). Estudi de cas sobre el tractament integrat del verb en una aula d'educació secundària. Bellaterra Journal of Teaching \& Learning Language \& Literature, 8(4), 43-61. DOI:

http://dx.doi.org/10.5565/rev/jt13.626 